\title{
Normativity in English oral production in Finland and Japan
}

\author{
Henna Paakki, University of Helsinki and Aalto University
}

\begin{abstract}
This research examines the effects of normativity on difficulties experienced with English oral production in Finland and Japan. Moyer's classification of factors influencing second language acquisition (2004) as well as language ideology theory (Garrett, 2010; Milroy, 2007) are used as a framework for an analysis of 56 semistructured interviews with Finnish and Japanese adult learners of intermediate level English. Self-reported experiences related to speaking English were annotated with appropriate codes and analyzed using content analysis. The results show that normativity related to the English language explains many of the difficulties learners experience with speaking English, and that this normativity is essentially connected to social factors as well as instruction and input factors in language learning.
\end{abstract}

Keywords: adult second language learning, language ideologies, sociolinguistics, oral proficiency

\section{Introduction}

Although English is a language studied extensively all over the world, many learners have difficulty speaking it (e.g. Kitao \& Kitao, 1995, pp. 3-16; Leppänen et al., 2009):

(1) I know English grammar and vocabulary well, and I've no great problems with understanding English when I listen to it or read it. However, when I have to speak English, the words just don't come out!

(Finland, informant 1)

As practical language skills are an important goal of language instruction, uncovering the reasons why speaking, in particular, inflicts undue stress upon English learners is an essential starting point for mitigating these barriers. Thus, this study ${ }^{1}$ aims at discovering the central factors contributing to such speech related difficulties by analyzing interviews with Finnish $(n=29)$ and Japanese adults $(n=27)$, who were studying English in their home countries at the time of the interviews. The semi-structured interview concentrated on self-reported experiences from English oral production. The data is studied using content analysis, and the resulting codes are analyzed more generally with the help of

Corresponding author's email: henna.paakki@aalto.fi eISSN: 1457-9863

Publisher: University of Jyväskylä, Language Campus

(C) 2020: The authors

https://apples.journal.fi

https://doi.org/10.47862/apples.99132 
Moyer's classification (2004; see section 2 for more details), to illustrate more general tendencies in the data sets.

There are many factors that contribute to learning and speaking a second language, as classified by Moyer (2004; adapted from Schumann, 1978):

1) neurological factors

2) affective and personality factors

3) cognitive and aptitude factors

4) instruction and input factors

5) social factors

Thus, speaking a foreign language is a complex process that requires not only theoretical knowledge of the target language (TL), but also practice of word and structure retrieval from memory, and motoric tasks like the production of phonemes that differ from one's first language (L1). However, learning to speak and speaking a foreign language is also influenced by language ideology closely connected to the target language and culture as well as the social context surrounding an individual. This is because language is the target of many implicit normative ideologies that stress prescriptive notions of what language should be like, how it should be used and what type of language is good or correct.

The main argument is that for many English learners, normativity is a key element in experiencing trouble with oral production. In this study, normativity refers to the idealization of standard TL accents, and standard TL models that are free from dialectal features, learner errors, spoken-language-like colloquialisms or imperfectness or non-standard grammar. Moreover, this norm-idealization involves a value judgment, where norm-abiding or norm-like production is superior in value compared to production that differs from the norm or fails to replicate it. Normativity can be seen in how learners conceptualize themselves as English speakers, what attitudes they possess toward the English language, how they wish to speak, how they position themselves in social interaction with nonnative and native speakers of English, and the levels of anxiety or stress related to speaking English (e.g. Jenkins, 2010). Therefore, the main research questions are:

1) What are the main sources of oral production related difficulties in the informants' experience?

2) What are the main factors contributing to TL related normativity?

3) How does normativity affect the informants' readiness for TL oral production?

\section{Language ideology theory in TL oral production}

Normative language ideology emphasizes the stabilization and conservation of language and linguistic purity: language is seen as a closed system that can be kept pure, standardized, counted and predicted, and not dependent on a given social context, relative and changing (e.g. Blommaert et al., 2005; Pietikäinen \& Kelly-Holmes, 2012; Pujolar, 2007). The effects of normativity can be seen in how the ideal target language is construed, e.g. aiming at native-like TL competence and accent. Normativity can be seen in the prevailing language ideology of the linguistic environment: e.g. instruction (Aro, Ruohotie-Lyhty, Kalaja \& Ferreira, 2015; Karrebaek, 2013) and social discourse (Garrett, 2010; Milroy, 2007). 
As a medium of global communication, the English language influences minority languages and cultures as a conveyor of language ideology (Garrett, 2010). Woolard (1998, p. 7) defines language ideology as "ideas, discourse or signifying practices in the service of the struggle to acquire or maintain power", and Milroy (2007, p. 133) argues that "language attitudes are dominated by these ideological positions that suppose an existence of a standard form of language, constituting the "ideology of the standard language" (Garrett, 2010, p. 7). Authorities further reinforce this uniformity, awarding prestige to language forms similar to the idealized standard (Garrett, 2010, p. 7; Milroy, 2007). Contrarily, differing forms are stigmatized, which makes people consider them non-standard and thus less prestigious (Preston, 1996).

This prestigious standard language is often seen as neutral, although its norms create juxtapositions between different groups (e.g. native vs. non-native: Hall, 1992), and majority (e.g. English) and minority languages and cultures (e.g. Finnish) (de Swaan, 2001). Thus, this ideology also affects English learners attempting to master the language. For example, foreign accented speech evidently triggers stereotypes that might not be connected to proficiency at all (e.g. Jenkins, 2007; 2010).

Community discourse often manifests ideas surrounding the norm (Bourdieu, 1991; Heller, 1995): the stereotypical "good speaker" of English is represented in macro level societal discourse, and in micro level discourse e.g. in classrooms and peer groups (Rydell, 2015). In majority settings and distance learning, the TL is studied and celebrated from a distance (Clément \& Kruidenier, 1983), and monolingualism and primary L1 socialization are regarded as ideals with no traces from other languages (e.g. no codeswitching, transfer, foreign accent) (Ortega, 1999). Aiming at this type of "double monolingualism" (cf. Cook, 1992) is problematic, as a person's L1 cannot and should not be erased (e.g. Jenkins, 2010). Moreover, social networks where the speaker has power to be heard are key in learning a language (Bourdieu, 1991; Lybeck, 2002, p. 176; Milroy \& Milroy, 1992), which is why community is essential in forming attitudes toward the TL. Learners with close TL networks are socially and psychologically less distanced from the TL culture and will learn the TL more easily than those with weak or passive networks (Lybeck, 2002, p. 176). Arguably, this influences how normative a stance they have toward the TL.

Normativity is often established in the ideology of educational settings (e.g. Karrebaek, 2013). For example, the traditional accuracy-oriented or GrammarTranslation approach does not ideally support oral fluency (Ellis, 2008). Speaking is a complex process that involves both physical and cognitive functions (Tatham \& Morton, 2006), knowledge of pronunciation, vocabulary, grammar, fluency, and pragmatic and socio-linguistic competence (Ellis, 2008). Spoken language also has its own grammatical features (Biber \& Quirk, 1999) and distinct cognitive processes (Harley, 2001, p. 374-400; Petersen et al., 1989), and so it must be practiced as much as other language skills. However, despite the interest in communicative methodologies, focus on written forms remains salient in education, and conceptualizations of spoken English are often based on written forms of English (Linell, 2005). Moreover, the speaking act is often seen as a performance evaluated by institutions, rather than communication aimed at delivering a message. This idea reflects normative ideologies such as the imagined "good speaker", "good accent" and "correct and good language" as well as the monolingual norm (Rydell, 2015). 


\section{Data and Methods}

A comparison of Finland and Japan allows an analysis of how two different (ideological) contexts influence an individual's readiness to speak English as a foreign language. Despite having non-Indo-European official languages and some cultural similarities (e.g. silence and politeness, cf. Garant, 1997), the countries have many ideological and cultural differences. These include low power distance vs. high power distance, individualistic vs. collectivist culture, different English education and linguistic environment, and differences in the status of English in society (Garant, 1997). On the other hand, these countries have their own similar hierarchies of language ideology, where the standard model of Finnish or Japanese is often idealized and minority dialects and accents are stigmatized (e.g. Nuolijärvi \& Vaattovaara, 2011; Okubo, 2009). Furthermore, both are classified as high-context cultures (Hall, 1992).

English has a stronger and more prestigious status in Finland and seems to be becoming more of a second language (L2) than a foreign language (FL) (Taavitsainen \& Pahta, 2003, p. 10). This exposure to English arguably has influenced Finns' attitudes towards English. In addition, Finns study approximately 2.2 languages at school (Kumpulainen, 2014), whereas in Japan English is "virtually the only FL offered" and the traditional GrammarTranslation approach still seems to be appreciated (Garant, 1997, p. 66). In Finland, language education has moved toward a more communicative model since the 1970s, after the Finnish informants' school years, which will arguably enhance functional and meaning-oriented oral production (cf. Garant, 1997; Hentunen, 2004, p. 17). However, English oral production still feels difficult for many learners (e.g. Leppänen et al., 2008; Ilola, 2018).

The data consists of semi-structured interviews with Finnish $(n=29)$ and Japanese $(n=27)$ adults studying English at an intermediate level, focusing on selfreported experiences from English oral production. Ages ranged from 40 to 62 , the average age being 53.6 years (Finns: 50.9, Japanese: 56.5), and the male to female ratio approximately 2:3. None of the informants were bilingual, all Finnish informants' L1 being Finnish and the Japanese informants' L1 Japanese. In Finland, data was collected in North and South Karelia, and in Japan in the Kyoto and Osaka area, i.e. non-capital areas with distinct dialects. A little under half of the Finns and a little over $60 \%$ of the Japanese had a university degree, and most informants had lived most of their lives in urban areas. Almost all Finnish informants had begun learning English at the age of nine, the Japanese at 12-13.

The interviews were conducted in the informants' native language, in order to avoid possible stress from speaking English. Most interview questions were open, mainly concerning the informants' educational history, experiences from speaking English, their use of English, self-reflections of difficulties experienced in speaking English, TL social networks, and attitudes toward the TL (see interview questions in the appendix). The average length of the interviews was approximately 40 minutes $(20-90 \mathrm{~min}$.).

The transcribed data was annotated and analyzed using content analysis to discover which factors were essential to the development of (self-confidence in) TL oral production skills. The annotations were assigned appropriate codes arising from the data. The coding was double-checked by the present writer in a second analysis, part of the data also analyzed by a research assistant to further validate the results. Frequencies of codes across both data sets were counted to illustrate overall tendencies. 
The coded data was further analyzed using Moyer's classification as a macroframework (2004, p. 15), in order to attain a better understanding of the most common general tendencies within both data sets that would point out the most problematic areas related to oral production. Neurological factors have to do with lateralization, i.e. maturational constraints (Moyer, 2004). They will, however, be excluded from the analysis as the research method is not ideal or reliable for analyzing the effects of neurological factors on speaking; the effects of onset age for TL learning on neurological factors can only be speculated on. There already exist various studies on lateralization (e.g. Ioup, 2008), and so this study concentrates on other inhibiting factors. First, affective and personality factors include motivation, ego permeability, tolerance for ambiguity, sensitivity to rejection and self-esteem, extroversion and introversion and culture shock (Moyer, 2004). Cognitive and aptitude factors include cognitive maturity and processes, strategies and styles, interference from L1 and field dependence and independence (Moyer, 2004.). Instruction and input factors refer to gained TL input, teacher and class dynamics and reaction to feedback, curriculum, intensity and duration of instruction, and saliency (Moyer, 2004). Finally, social factors mean group or community level factors, such as status, assimilation and acculturation, preservation of ethnic and cultural identity, type of community, attitudes toward target language group, and personal level social factors, for example transition anxiety (from L1 context to TL social context), social strategies and linguistic shock (Moyer, 2004).

\section{Complexities of normativity in TL oral production}

Overall, most informants considered speaking English as difficult. The results emphasize the role of TL related normativity in experiencing difficulties with TL oral production, thus supporting this paper's main argument. First, factors contributing to difficulties with speaking the TL will be discussed in general, comparing the overall differences between Finnish and Japanese data. Next, the most central contributing factors, social factors and instruction and input factors, will be discussed in detail as presented in Table 1:

Table 1. Central factors contributing to normativity and difficulties in TL oral production.

Input and instruction factors
1. Scarce TL input and use
2. Standard model and accuracy-oriented
instruction

Input and instruction factors instruction
Social factors

1. Normative ideology of English accents

2. Norms concerning communicative

competence

3. Social pressure

\subsection{Factors affecting English oral production}

Most of the informants felt that speaking English was (sometimes) difficult ( $90 \%$ of the Finns and $85 \%$ of the Japanese), and to many it was or had been extremely so. Speaking was regarded as enjoyable by only $25 \%$ of the Finns and $48 \%$ of the Japanese, and unenjoyable by 18\% (Finland) and 33\% (Japan). Speaking English often involved insecurity (number of coded annotations relating to insecurity respectively: Finland 87 - Japan 50), anxiety (Finland 44 - Japan 24) and other 
negative feelings, such as a fear of errors (F27 - J7) or self-criticism toward one's own speech (F39 - J22). Interestingly, the Finnish informants reported more insecurity with speaking English than the Japanese, which might be due to a generally higher proficiency level in passive skills, or more exposure to and understanding of the TL (see 3.2.1). They often spoke of experiencing "a threshold" in speaking, whereas the Japanese said their English "does not come out" ("出 $\tau$ こない”).

It can be concluded from the content analysis and further classification of codes into parent-categories that the most central factors that contributed to difficulties in English oral production were related to social factors, and instruction and input:

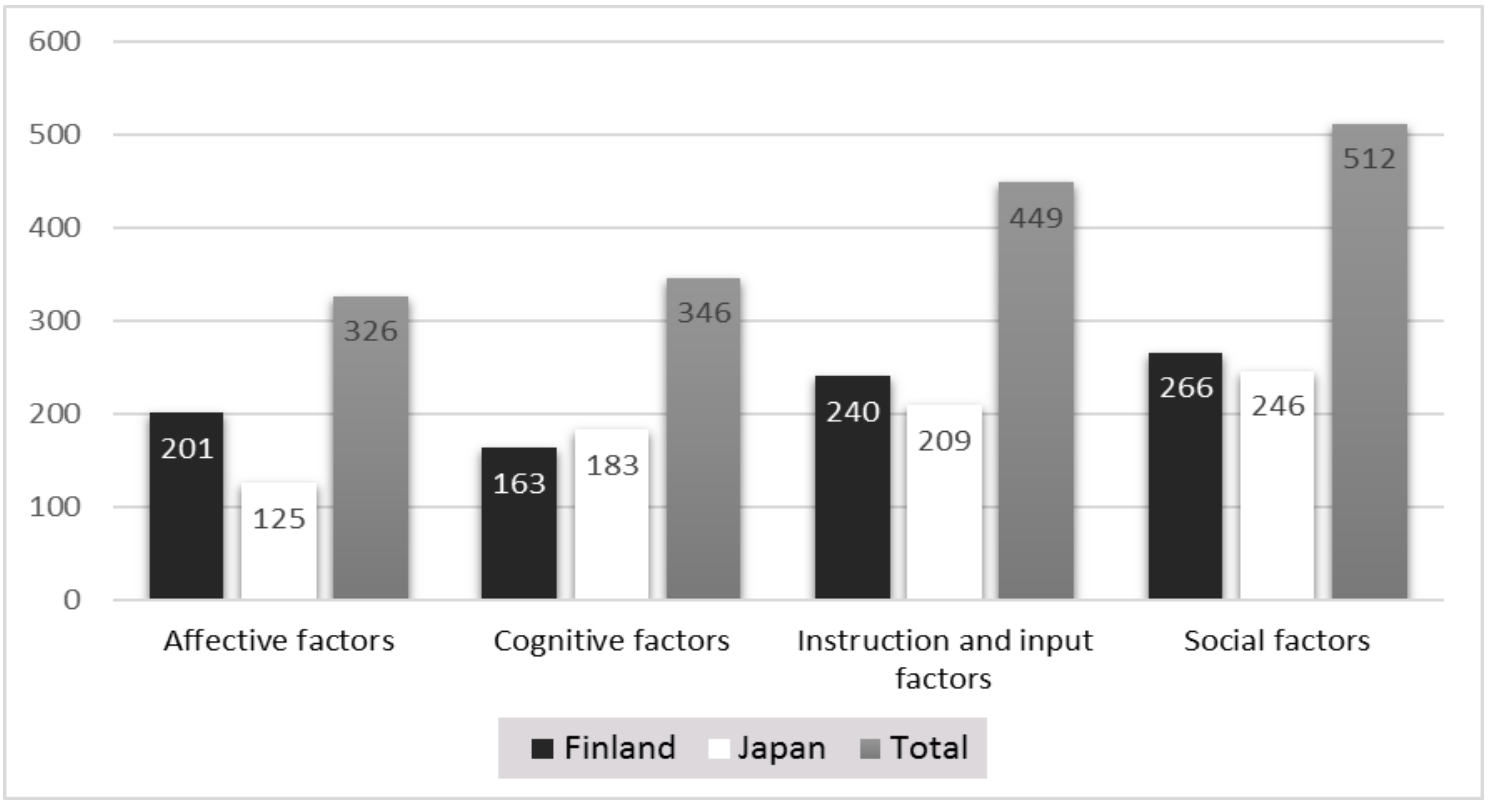

Figure 1. Factors contributing to difficulties in oral production: number of codes classified into corresponding parent-categories.

Figure 1 illustrates the most central differences between the two countries. Firstly, the Japanese informants reported more cognitive factors than the Finnish informants, most importantly comprehension (Finland 25 - Japan 58) and pronunciation related difficulties (F30 -J34). It is also noteworthy that the Finnish data showed more insecurity, experience of level difference when speaking English with others (especially native speakers), fear of errors and a higher attention to accuracy, despite having more experience in studying English than the Japanese informants. This was arguably due to contextual differences (see 3.2.). Fewer codes were assigned to the Japanese data overall, which might have been due to a lack of experience with the TL or the researcher's outgroup status. In effect, a higher percentage of the Japanese reported having very basic English skills (F1 - J11), and little experience from speaking (Lack of use: F32 - J45), which might have made it difficult for them to analyze their own English usage in detail. Most Japanese informants had greatest trouble with listening comprehension:

(2) ... on a trip, looking at how I'd spoken I felt really frustrated, but like, I had a terrible complex, and so until now I just haven't been able [to speak]. I can't understand at all and I'm terrible at speaking, even my Japanese is bad, so I was told English is impossible for me. 
The Japanese sometimes saw speaking as easier than listening, because they were able to decide the flow of the conversation themselves, whereas Finns mostly saw English oral production as most challenging. It is highly possible that maturational constraints underlie these differences in comprehension and pronunciation difficulties, as the Japanese had commenced their English studies 3-4 later than the Finns. However, this paper will concentrate on analyzing other factors.

Social factors and instruction and input factors were most central in the data, possibly due to their role in socializing the informants into the TL community. For those lacking contact and involvement in TL networks outside of school, English instruction seemed to be the main contributor to how normative a view they had toward the TL. This was essentially determined by social phenomena related to language, such as language ideology, prestige, status, and peer pressure. This can be seen in the most frequent codes within the data sets (see full code table and descriptions in the appendix):

Table 2. Most frequent codes in the content analysis of the Finnish and the Japanese data sets.

\begin{tabular}{llll}
\hline Code (factor) & Finland & Japan & Total \\
\hline Accent bias (social) & 93 & 63 & 156 \\
Insecurity (affective) & 87 & 50 & 137 \\
Comprehension difficulties (cognitive) & 25 & 58 & 83 \\
Accuracy bias (instruction and input) & 62 & 20 & 82 \\
Peer pressure (social) & 46 & 33 & 79 \\
Lack of use (instruction and input) & 32 & 45 & 77 \\
Grammar-Translation method (instruction) & 44 & 29 & 73 \\
Standard model bias (instruction and input) & 36 & 33 & 69 \\
Anxiety (affective) & 44 & 24 & 68 \\
Memory retrieval difficulties (cognitive) & 40 & 24 & 64 \\
Pronunciation difficulties (cognitive) & 30 & 34 & 64 \\
Self-criticism toward own speech (affective) & 39 & 22 & 61 \\
Lack of speech practice (instruction and input) & 30 & 31 & 61 \\
Weak ties to TL community (social) & 15 & 35 & 50 \\
Level difference (social) & 28 & 10 & 38 \\
Linguistic shock (social) & 7 & 30 & 37 \\
Lack of exposure (instruction and input) & 9 & 26 & 35 \\
Fear of errors (instruction and input) & 27 & 7 & 34 \\
\hline
\end{tabular}

Normativity was central in experiencing trouble with TL speech. Instruction and input had often promoted a normative model of the TL (monolingual, standard model, textbook model, native accent), leaving the informants passive agents and outsiders in TL use. Thus, many problematic beliefs about the TL originated from the informants' social and instructional context: many conceptualized their own TL production as deviating from the norm and thus subordinate to the given TL model or native TL production. The few informants who saw their English production as approximating the normative model seemed to feel somewhat more confident in speaking the language, although still feeling stressed about e.g. their accent. 


\subsection{Instruction and input}

For many, English instruction and English input through media were their only contacts with the TL, which is why they were crucial to the development of TL skills and to forming a relationship with the TL. Based on the content analysis, it seems that, most importantly, scarce TL input and use, as well as standard model and accuracy-oriented instruction had influenced normativity related to the TL: how normative of an understanding informants had of TL accents and standard models, and the emphasis they put on accuracy.

\subsubsection{Scarce TL input and use}

The English input informants had received in their everyday lives had considerably influenced their attitudes towards English and their relationship with the language. The Finns had been exposed to English a lot more in their daily lives than the Japanese, who often lacked input (Lack of exposure, Finland 9 Japan 26). This was due to context-dependent factors, such as the high visibility of English media in Finland vs. a lack of English exposure in Japan, as well as differences in English usage in everyday life. Finns used English quite a lot in their free time (movies, internet etc.), some even to communicate with friends and/or relatives. The Japanese informants had a more distant relationship with English (Passive or no TL networks: F15 - J45), as they had mostly been exposed to Japanese media, English movies having been dubbed. However, in both groups English was often in passive use, lacking active practice of spoken English (Lack of use: F32 - J45). This seemed to further emphasize normative models of the TL, as the informants did not have alternative models, lacking exposure to different varieties of the TL and its colloquial forms.

In addition, a general exposure to foreign languages seemed to have influenced the informants, as for the Finns studying several foreign languages was common (Swedish, German, Russian, French etc.), whereas the Japanese had studied hardly any other FL besides English. This might also have been a significant factor contributing to the Japanese informants' difficulties with listening comprehension and their distanced relationship with the TL, as exposure to FLs had been highly scarcer and had commenced later than in Finland (see Ioup, 2008; Lenneberg, 1967).

The Finns' versatility in FL studies and exposure to the TL had arguably contributed to the development of their listening comprehension skills, interest in FLs, and general linguistic knowledge. However, oral production still proved to be problematic, which seemed to be partly due to differing levels in their grammatical and comprehension skills as compared to their active oral production skills. Arguably, the lack of practical experience emphasized normative models provided by social and instructional environment. More in particular, as English had a more comprehensive role in their everyday lives (although often as passive recipients), they had a wider understanding of the versatility of the English language (accents, dialects, standards etc.), and thus a more elaborate idea of what their English should sound like. However, they mostly did not see this expectation as symmetrical with their actual oral production, as the already learned exhaustive grammatical and vocabulary contents seemed to demand better performance from them. This conflict between the norm and their self-perceptions as TL speakers created pressure in oral production. 


\subsubsection{Standard model and accuracy-oriented instruction}

Earlier English instruction was a central theme in the interviews, as it had been one of the earliest bridges between the informants' daily lives and the TL culture, even now creating preconceptions of the TL:

(3) It's like my head's confused and there are many different thoughts, like how should I say it. It's not a feeling of having fun when speaking. It feels like studying, that's what it is.

(Japan, informant 4)

A source of problems was the normative language ideology within instruction, emphasizing accuracy, written and standard models, and low TL autonomy or agency. Within both data sets the instructional context had been characterized by a 'Grammar-Translation method' (F44 - J29) and an 'Accuracy bias' (F62 - J20). In other words, in both countries English had been studied mainly by reading a textbook, translating sentences and studying grammar, with very few oral exercises (Lack of speech practice in education F30 - J31), test taking dominating language education, emphasis being mostly on accurate production rather than fluency. Committing errors (Fear of errors F27 - J7) was seen or had been seen as a grave matter:

(4) A: Is it fun to speak?

B: It is now, but it wasn't before.

A: Why?

B: Because of the style back then because it was just horrible, Swedish was too but the teacher was supportive, we didn't think about being understood back then.

A: Did that create pressure?

B: Well it has caused that I had a 30-year pause but now then that I have relatives who don't speak Finnish.

A: So it's a must?

B: Yes. I've had private teaching for 1.5 years, earlier I didn't open my mouth.

A: Why?

B: Because of the errors. And when you think that this is how it goes but then you say something totally horrible. Pronunciation is still horrible.

(Finland, informant 4)

This had affected the informants considerably: many informants mentioned imagining their teacher's red pen correcting them when having to speak English, and speaking was often seen as more of a performance than communication (as in Rydell, 2015). This created anxiety in oral production. Although the Japanese instructional context had been similarly problematic, it seemed to have involved a more distant relationship with English, as sometimes even the teacher had not been able to speak English or had not had the preferred accent. Interestingly, the Japanese did not seem as concerned about errors in oral production. This might have been due to their main difficulties being related to comprehension and their lack of experience, or possibly a wish to save face in front of the researcher.

Also, normativity in the written bias in language instruction seemed to have created a conceptualization of spoken English as a representation of the written form: many informants seemed to believe that their spoken English should be like their written, grammatically correct and elaborate textbook sentences. A native speaker's oral production was often seen as perfect and standard-like, contrarily 
to real-life conversations, whereas in actuality spoken language differs from written language considerably in grammar, structure and style, as pauses, slips and deviations from the norm occur regularly even in native speaker production (cf. Biber \& Quirk, 1999).

In general, instruction seemed to have promoted a normative and distanced rather than functional relationship with the TL. The normative ideal seemed to be monolingual, standard model and accent-centered, accuracy-oriented and even perfectionist (Standard model bias F36-J33, Accent bias F93-J63). This ideal proved highly problematic in actual oral production situations as it reduced willingness to speak:

(5) A: So the fear of errors made it difficult?

B: Yes, that was exactly the big problem, and especially for my age group that you should have known everything precisely before saying it.

(Finland, informant 5)

The learning context was also socially distanced from the TL, and this outsider-view of the TL had not supported functional oral skills. Legitimate oral production seemed to be defined according to the level of accuracy of English produced in the classroom, which was a point of conflict in real-life conversations. Overall, the role of instruction was important not only in the development of oral skills, but also in the development of attitudes towards the TL and the informants' confidence as its users. On the other hand, a teacher's supportive, functional attitude was apparent within the data collected from a Finnish group in South Karelia: it had helped many to overcome their fears of not being able to fulfill the norm:

(6) The most important thing is to be understood.

(Finland, informants 3, 5-7, 9, 11-14)

\subsection{Social factors}

Social factors are essential in explaining difficulties experienced in TL oral production. Central conflicts were related to norm-induced pressure of wanting to speak standard-like English with a native-like accent, acquiring native-like social and communicative competence, and social pressure experienced in getting access to TL social communities and getting positive evaluations from peers.

\subsubsection{Normative ideology of English accents}

Firstly, normativity related to English accents was central in experiencing inhibition in speaking English, as the standard model bias and an idealization of standard accents created pressure in practical speech situations. This could be seen in the prestige or stigma (Preston, 1996) informants awarded to different English accents.

The standard language ideology represented in earlier education seemed to have had a considerable effect on the informants, as the perceived superiority of standard English accents was often visible in the interviews (Accent bias F93-J63), and Standard British English was often seen as the goal of learning English. Somewhat similarly to young Finns' views in Ilola (2018), overall a lot of emphasis was put on pronunciation in oral production. Access to user communities is essential in developing oral skills, but this seemed to involve an idea of having to adopt a native-like accent in order to become a "good" user (as in Jenkins, 2010). 
However, this is an unrealistic goal, because even for advanced learners learning to speak with a near-native accent is a highly complicated task (cf. Ioup, 2008). Thus, accent might be a factor excluding FL speakers from a TL community, complicating contact with the TL community. It seemed to be implied that native speakers "own" the language, whereas learners only attempt to copy them instead of expressing their own thoughts independently. In addition, a wish to efface one's nationality (through accent) was often salient in the interviews, which seemed to imply that the goal of language learning was a type of "double monolingualism" (Cook, 1992), lacking appreciation of the informants' bi- or multilingual abilities.

Language use deviating from the standard model was often stigmatized. This implied a hierarchy, where the prestige language determined the norms, its community perceived as possessing power and prestige (Prestige F13-J18):

(7) B: James Bonds these old ones, they have pure English.

(Finland, informant 9)

(8) A: Is it embarrassing (speaking with a Finnish accent)?

B: Well not embarrassing, but people want to become one with the crowd, like I'm from Finland and I have this kind of stupid English, one speaks business English like that (not with a Finnish accent).

(Finland, informant 2)

The stigma, on the other hand, could be seen in the attitudes toward the Finnish and the Japanese accents of English that were implied to be incorrect or illegitimate:

(9) A: What do you think of the Japanese accent of English?

B: I've never grown accustomed to something like that.

A: Why do you think that is?

B: I've always thought that I'd like to learn how to speak real English.

(Japan, informant 8)

Similarly, although some Japanese evaluated themselves positively, the informants' attitudes toward their own spoken English were mostly negative (Self-criticism toward own speech F39 - J22):

Table 3. Examples of informants' self-evaluations of their own spoken English.

Finnish informants

Sounds like stuttering

Unclear muttering

Tankero, not like English

Mika Häkkinen-like tankero English

Tankero, comical

Terrible, can't pronounce

Awkward, I like to stay silent

Medium level tankero
Japanese informants

Embarrassing, don't want to accept reality

Embarrassing, can't do the sounds properly

If I could talk it might be fun to hear

Useless, I'm no good, impossible

It ends up like Japanese English unfortunately

Normal, doesn't really change

It must be amazing

Weird 
This implied a conflict between the norm and the informants' actual oral production. The distinction between the Finnish/the Japanese usage of English and the standard model norm was further established in the naming of interlanguage variants (katakana English, wasei-eigo, tankero English, and racecar driver English2, which seemed to label Finnish or Japanese sounding English with social stigma, and even a notion of common shame and exclusion from the TL community. These attitudes were facilitated in social practice e.g. by peers:

(10) My wife and my young daughter always pick on me about my English, the way I speak, I guess it's because it's a kind of tankero English, and then if I forget some words then I guess it's funny.

(Finland, informant 2)

\subsubsection{Norms concerning communicative competence}

Idealizing the norm also involved a wish for native-like social and communicative skills. For example, cultural differences or awkwardness in interaction were sometimes unjustly blamed on low proficiency:

(11) B: -- I was visiting Turkey and tried to speak with Turks and then my student colleague said hey, I can't understand what you're saying at all. I thought that well then maybe it's better that I don't even try to talk to those Turks then all the worse, I got the feeling that this is what you get for trying that even that colleague said that this isn't working at all.

(Finland, informant 2)

Not being used to FL communication in general seemed to affect the informants' English oral production and their self-evaluations. They had not developed communication strategies like nonverbal strategies for coping with international communication, or for situations requiring paraphrasing, for instance. Moreover, possibilities for speaking English often emerged as a surprise, for example when a tourist in the informants' local neighborhood asked them for directions. Most saw the sudden switch from L1 to the TL as very difficult and quite many as stressful, because they felt their English proficiency was not good enough since the switch did not happen easily or almost automatically.

Many informants also reported experiencing limited self-expression (F18 - J12), slowness, and feeling "stupid" or "child-like":

(12) A: Is it difficult [to speak English]?

B: It is, and there are some important things that you want to explain but the words run out, but it's annoying that you like sound like a little child, when you speak a foreign language, like you can't be taken seriously because it most likely doesn't... makes you feel a bit stupid.

(Finland, informant 1)

This seemed to involve an idea of one's TL speech as a direct representation of their mental activities, poor performance thus showing low mental capacity, although such interconnection between TL usage and mental reality is far from inferential. Altogether, developing TL speech seemed to require the courage to jump into spontaneous situations that often do not function similarly to L1 communication, and that often put the informants in quite an unfamiliar communicative position or role. 


\subsubsection{Social pressure}

Social community was essential in developing confidence in one's TL oral skills, both in gaining access to TL social communities (native and non-native), and in gaining evaluations from one's peers. Firstly, gaining access to TL communities was important in getting alternative TL models, building confidence as a TL user, and overcoming the pressure of norms:

(13) Once at a campfire there happened to be a young Dutch couple, and I liked it that we could chat, when you're not too pedantic, like if it's another foreigner then they don't speak that perfectly either.

(Finland, informant 18)

Strong social networks can be seen as essential to the development of oral production, as those with distant ties to the TL (Weak TL networks, F15 - J45; Lack of use, F32 - J45) seemed more insecure with their English oral production, as compared to those with closer ties: codes referring to weak ties or no ties were often shown together with more problematic codes like accent or accuracy bias or self-criticism or insecurity. Few informants had strong TL contacts, but quite many had some contacts, 5 Finns and 7 Japanese having strong or close contacts, and 33 and 45, respectively, having some interactive TL networks. However, gaining access to native TL speaker communities was often difficult. Although (or because) standard models were idealized, communication with native speakers was often seen as stressful, sometimes involving a feeling of exclusion (Exclusion from the TL community: F8 - J8):

(14) A: Is there a difference in how native speakers react to [you] speaking [English] compared to others?

B: I don't know if it's just a supposition that they're more critical and laughing on the inside, they don't do it perfectly either, it's just the feeling one has.

(Finland, informant 18)

(15) B: When I was in Australia, as expected, like, the Japanese accent of English, when it wasn't this type of smooth English, I was made fun of a bit and such, there was that too, well, there are those kinds of people too.

A: Does that bother you?

B: Yes it does. It does, but if you're bothered by it too much, it just doesn't work.

A: If you're made fun of, does it make you stop speaking?

B: Yes, once you hesitate and stop speaking, you end up thinking ok so I won't say anything anymore, but in the end I have to speak or I have to deliver a message, so I speak. It was good that I had to speak.

(Japan, informant 52)

Normativity can be seen in how the informants above positioned themselves as English speakers as compared to native speakers. It seemed to create a feeling of exclusion and a feeling of remaining on a "different level" compared to native speakers (Level difference: F28 - J10). Speaking with native speakers was sometimes seen to be easier if they also attempted to speak some Finnish or Japanese. However, speaking with other non-native speakers was often considered more comfortable (F20 - J6), as they were "on the same level" (approximately 30 mentions in the Finnish data, 4 in the Japanese): 
(16) On the same starting level, that's right, everyone has their own accent, --- we are, like, at the same level.

(Finland, informant 7)

This phenomenon was more characteristic of the Finns, possibly because they had used English more often and so had more experiences to talk about. The Japanese informants, on the other hand, reported having trouble with speaking English because of a linguistic shock (F7 - J30), e.g. due to stress related to significant differences between the TL and one's L1, or socializing with non-Japanese people:

(17) B: Yes, there's the embarrassment. But, speaking like this, normally with Perry [the teacher], one notices that foreigners are also normal people.

(Japan, informant 31)

On the other hand, peer pressure (F46 - J33) complicated English oral production. For example, many informants were concerned about portraying low English proficiency in the eyes of their peers (also in example 9):

(18) -- if I'd know that everyone else is terribly good [at English], one would think that I'd then go stammer stammer, so then I probably wouldn't open my mouth.

(Finland, informant 14)

Many, who were worried about their peers' evaluations of their English, dared not speak in front of them. In the Finnish context, specifically the belief that "everybody knows English" created peer pressure, along with accent and standard model related attitudes. Other central social beliefs that caused anxiety in TL oral production included the idea that Finns are "shy and incompetent communicators", and that English speech is learnt by "just starting to speak it" or "going where it is spoken". In the Japanese context, peer pressure was also a problem. For instance, the idea that Japanese people "cannot speak English very well" seemed to create some peer pressure in oral production. However, contrarily to the Finns, the Japanese were sometimes admired by their peers for their attempts to speak English, because studying or speaking English was rarer in Japan at least among the informants' generation.

On the other hand, positive social relations had decreased the pressure of normativity and normative beliefs about the TL: those with strong relations with the TL community or with individuals conceptualized as members of the TL social group more often had less trouble with speaking. Their attitude toward the TL was less normative and stressed the importance of communication and functionality.

\section{Discussion and conclusions}

The main argument of this paper was that normativity related to the TL significantly affects TL oral production, the results supporting the argument and the main ideas of language ideology theory (Milroy, 2007; Garrett, 2010). A key element in experiencing difficulties in English oral production was how normative an individual's stance toward the TL and their own speech was: a more lenient attitude also showed more self-confidence or readiness to speak as compared to a highly normative one. Most informants aimed at the normative ideal, which proved to be a source of conflict in real-life speech situations, as many felt anxious about their own production differing from the TL norm. 
The most important sources of this normative ideology and thus difficulties experienced in speaking the TL were input and instruction and social factors. Firstly, exposure to the TL greatly influences a learner's familiarity with the TL. Also, language instruction might focus too heavily on accuracy and standard models, which emphasizes a normative attitude toward the TL rather than encouraging the development of functional and independent oral skills: in both Finland and Japan the earlier Grammar-Translation method and a lack of active speech practice had proved problematic in TL oral production. Secondly, social community plays a significant role in TL speech development. It determines if and how people may gain access to TL social groups to practice speaking, instead of only concentrating on accuracy and standard models or worrying about (peer) assessments (somewhat like in Ilola, 2018).

The contextual differences between Finland and Japan are significant in explaining the Finns' and the Japanese informants' differing attitudes to speaking the TL. In Finland, English oral production surprisingly seemed to involve more pressure and insecurity. Finns seemed to have often adopted a role as passive agents, as comprehension was easy, they were passively involved with the TL quite often, and had an extensive repertoire of vocabulary and grammar knowledge. However, along with a lack of oral practice and a normative, institutionalized top-down view of the TL, the asymmetry between their oral skills and their comprehension skills seemed to inflict pressure in speaking the TL. This was often due to having quite a high awareness of English standard models and accents, and a normative, elaborated idea of how one should or would like to speak, which conflicted with the informants' actual production. On the other hand, the Japanese data was characterized by a more distanced relationship with the TL, and more comprehension problems due to a lack of exposure, international contacts, and overall FL study. They experienced more linguistic shock and many reported having very basic English skills, comprehension being their main problem. There were greater individual differences within the Japanese data, however, as some individuals were a lot more confident as speakers of English thanks to close contacts with the TL community.

When considering the results of this article, it has to be noted that some nuances may have been lost in the Japanese interviews due to the researcher's status as a non-native Japanese speaker. However, a native Japanese speaker would not have been perfectly immersed in this study and the analysis of the Finnish data. This was important considering the structure of the interview and a possible need for elaborating questions. Also, the coding and further categorization into parent categories is partly limited in the sense that it is at times interpretative, and some codes could in some cases be placed into two different categories. However, the categorization functions in the analysis to give a general idea of overall tendencies within data to help the reader.

There were also differences between the English education the Finnish and the Japanese informants attended at the time of the interviews: although they were all enrolled in intermediate courses, their English levels were often quite different, the Finns being generally more advanced and experienced. This might influence comparative analyses to some extent, e.g. people possibly being more self-critical on a higher skill level. Optional English studies were rarer for adults in Japan, which is why finding informants was hard. Furthermore, most informants voluntarily participated in English courses, and thus should have a relatively positive attitude toward English; interviews with people not partaking in English 
courses would likely yield different results. In addition, the informants' selfreflections in the interviews are highly subjective, some distant memories likely imperfect and/or affected by peer or societal discourse or new experiences, and self-analysis possibly restricted by affective factors or limited experience with the TL.

The results of this study show that normative language ideology has a tremendous effect on the users of a language, not only native but also non-native users learning the language. Furthermore, normativity seems to increase an individual's psychological and social distance to the TL, manifesting often as anxiety or insecurity in oral production. As depicted by language ideology theory (Garrett, 2010; Milroy, 2007), standard language ideology creates value differences among language varieties, and barriers between language users who master the standard and those whose language variety differs from it. Moreover, it is not only the emphasis on standard varieties, but also an emphasis on accuracy on the cost of functionality that may create barriers between language learners and the TL. Of course, standard models often enable communication as they create a general form of a language that different speakers can use, and help instruction to concentrate on one or two models instead of a plethora of TL varieties. On the other hand, they often create problematic value implications by acting as a point of reference and thus suggesting that non-standard production is unsatisfactory or illegitimate.

A written language bias (Linell, 2005) is problematic in TL instruction, because given models often represent the written Standard English model instead of the distinct dynamics of actual spoken conversations (Biber \& Quirk, 1999). This seems like a poor model for TL oral production, as efforts to produce textbooklike spoken English will easily fail and produce negative self-evaluations (cf. Rydell, 2015), especially if these concerns stop learners from speaking the TL in practice. Theoretical knowledge does not suffice to make one a fluent speaker of a new language, as understanding vs. speaking that language require practical rehearsal of differing cognitive processes (e.g. Harley, 2001, p. 374-400; Petersen et al., 1989). Lack of speech practice exacerbates the problem, as speech skills do not develop automatically.

Those who are regularly exposed to social interaction with English speakers (native or non-native) are likely to have less difficulty with speaking, as opposed to those who have less contact with English speakers. The latter group seems to be likelier to lean towards the norm more often. Therefore, just as social networks where the speaker has power to be heard are key in learning a TL (Lybeck, 2002, p. 176; Milroy \& Milroy, 1992), they also seem to be central in overcoming the pressure of normativity, developing confidence as a speaker of English. A distanced relationship with the TL might result in a one-dimensional and normative view of the language that relies too heavily on standards, not considering the differing features of spoken language. It also creates unrealistic impressions of how people speak the TL in real life, which might complicate speaking if one concentrates on finding the "correct" way to express an idea, instead of developing self-confidence in using the TL creatively.

In accordance with language ideology theory (Garrett, 2010; de Swaan, 2001), the status a language has in a given context significantly influences how normative a stance people have toward it. As compared to Japan, in Finland English has a stronger status often associated with intellectuality, internationality and even success, which creates a normative frame for expectations about using 
the language. Although the Finnish informants in this study were more experienced, they were also more anxious about speaking English than the Japanese. Thus, extensive exposure to the TL along with a lack of functional practice and TL social contacts seems to increase normative attitudes toward speaking the TL. This implies that: a) a higher awareness of the TL and norms related to its standard use create more pressure in TL oral production, b) a higher status of the (foreign) TL within one's social context assigns greater emphasis and prestige to norm-abiding TL use, thus creating pressure in speaking, and/or c) a greater asymmetry between speech skills vs. other skills also increases speech related difficulties.

To conclude, developing confidence in TL oral production is very much subject to how we deal with ideologies concerning the language: whether the approach to production is pedantic or more lenient, and whether we recognize that spoken language can be, and often is, imperfect, even in native speaker usage. Also, inhibition or pressure in TL oral production is not only due to accent issues uncovered by previous research (e.g. Jenkins, 2007; 2010), but also more generally dependent on how normative a stance one has toward the TL, e.g. related to accuracy, written-language bias, native-like production and communicative competence. Therefore, to encourage TL speaking, instruction should concentrate more on oral proficiency, and emphasize functionality, content, spoken TL models for speech practice, strategic communication skills and access into TL communities. Possible encouraging methods for overcoming difficulties with TL speech should thus be studied and developed further in future research. More research is also needed to study some of the arguments deriving from the results of this study, as well as the various other factors affecting TL oral production. 


\section{Endnotes}

1 This study was partly funded by the Academy of Finland (project number 256825). Thanks to Minna Palander-Collin and Sanna-Kaisa Tanskanen for the review and critique of this article.

${ }^{2}$ Katakana English refers to English loanwords, and Wasei-eigo to Japanese-language expressions based on English words (Miller, 1997). The term tankero English refers to a heavy Finnish accent of English (cf. Paakki, 2013). Although these terms, used to refer to interlanguage variants, might cause stress in oral production, evidently they might also have a liberating effect (Taavitsainen \& Pahta, 2003).

3 The original interview was conducted in Finnish in Finland and in Japanese in Japan and was somewhat modified to fit specific contextual needs.

\section{References}

Aro, M., Ruohotie-Lyhty, M., Kalaja, P., \& Ferreira, A. M. (2015). Beliefs, Agency and Identity in Foreign Language Learning and Teaching. New York: Palgrave Macmillan.

Biber, D., \& Quirk, R. (1999). Longman Grammar of Spoken and Written English. London: Longman.

Blommaert, J., Collins, J., \& Slembrouck, S. (2005). Spaces of multilingualism. Language and Communication, 25(3), 197-216.

Bourdieu, P. (1991). Language and Symbolic Power. Cambridge: Harvard University Press.

Clément, R., \& Kruidenier, B. G. (1983). Orientations in second language acquisition: I. The effects of ethnicity, milieu and target language on their emergence. Language Learning, 33, 273-91.

Cook, V. (1992). Evidence for multicompetence. Language Learning, 42, 557-591.

De Swaan, A. (2001). Words of the World: The Global Language System. Cambridge: Polity Press.

Ellis, R. (2008). The Study of Second Language Acquisition. Oxford: Oxford University Press.

Garant, M. D. (1997). Intercultural teaching and learning: English as a Foreign Language Education in Finland and Japan. University of Jyväskylä.

Garrett, P. (2010). Attitudes to Language. New York: Cambridge University Press.

Hall, S. (1992). The question of cultural identity. In S. Hall, D. Held, \& A. McGrew (Eds.), Modernity and its futures (pp. 274-316). Cambridge: Polity Press.

Harley, T. A. (2001). The psychology of language: from data to theory (2nd ed.). Psychology.

Heller, M. (1995). Language choice, social institutions, and symbolic domination. Language in Society, 24, 373-405.

Heller, M. (2007). Bilingualism: a Social Approach. Basingstoke: Palgrave Macmillan.

Hentunen, A.-I. (2004). Rakennetaan kielitaitoa. Käytännön konstruktivismia kieltenopettajille. [Building language skills. Practical constructivism for language teachers]. Helsinki: WSOY.

Ilola, M. (2018). Oppilaiden käsityksiä englannin suullisesta kielitaidosta, sen oppimisesta ja arvioinnista. [Pupils' beliefs about English oral proficiency, its learning and assessment]. Jyväskylä: University of Jyväskylä.

Ioup, G. (2008). Exploring the role of age in the acquisition of a second language phonology. In J.G. Hansen Edwards, \& M.L. Zampini (Eds.), Phonology and Second Language Acquisition (pp. 47-62). Amsterdam: John Benjamins Publishing Company.

Jenkins, J. (2007). English as a Lingua Franca: attitude and identity. Oxford: Oxford University Press.

Jenkins, J. (2010). (Un)pleasant? (In)correct? (Un)intelligible? ELF speakers' perceptions of their accents. In A. Mauranen, \& E. Ranta (Eds.), English as a lingua franca: studies and findings (pp. 10-36). Newcastle: Cambridge scholars.

Karrebaek, M. S. (2013). 'Don't Speak like That to Her!': Linguistic Minority Children's Socialization into an Ideology of Monolingualism. Journal of Sociolinguistics, 17, 355-375.

Kitao, K., \& Kitao, S. K. (1995). English teaching: Theory, Research, Practice. Tokyo: Eichosha.

Kumpulainen, T. (2014). Koulutuksen tilastollinen vuosikirja 2014. Koulutuksen seurantaraportit 2014: 10. Helsinki: Finnish National Agency for Education. 
Lenneberg, E. (1967). Biological Foundations of Language. New York: Wiley \& Sons.

Leppänen, S., Pitkänen-Huhta, A., Nikula, T., Kytölä, S., Törmäkangas, T., Nissinen, K., ... Jousmäki, H. (2009). Kansallinen kyselytutkimus englannin kielestä Suomessa: Käyttö, merkitys ja asenteet [National Survey on the English Language in Finland: Uses, Meanings and Attitudes]. Jyväskylä Studies in Humanities 132. Online: http://www.helsinki.fi/varieng/series/volumes/05/evarieng-vol5.pdf

Linell, P. (2005). The written language bias in linguistics: its nature, origins and transformation. London: Routledge.

Lybeck, K. (2002). Cultural Identification and Second Language Pronunciation of Americans in Norway. The Modern Language Journal, 86, 174-191.

Miller, L. (1997). Wasei-eigo: "English loanwords coined in Japan". In J.H. Hill, P.J. Mistry, \& L. Campbell (Eds.), The Life of Language: Papers in Linguistics in Honor of William Bright (pp. 123-139). Walter de Gruyter \& Co.: Berlin.

Milroy, J. (2007). The ideology of standard language. In C. Llamas, L. Mullany, \& P. Stockwell (Eds.), The Routledge companion to sociolinguistics (pp. 133-139). London: Routledge.

Milroy, L., \& Milroy, J. (1992). Social network and social class: Toward and integrated sociolinguistic model. Language in Society, 21, 1-26.

Moyer, A. (2004). Age, Accent, and Experience in Second Language Acquisition: An Integrated Approach to Critical Period Inquiry. Clevedon, GBR: Multilingual Matters Limited.

Nuolijärvi, P., \& Vaattovaara, J. (2011). De-standardisation in progress in Finnish society? In N. Coupland, \& T. Kristiansen (Eds.), Standard Languages and Language Standards in a Changing Europe (pp. 67-74). Novus Press: Oslo.

Okubo, Y. (2009). The localization of multicultural education and the reproduction of the 'native speaker' concept in Japan. In N.M. Doerr (Ed.), The Native Speaker Concept: Ethnographic Investigations of Native Speaker Effects (pp. 101-132). Berlin, Boston: De Gruyter Mouton.

Ortega, L. (1999). Language and equality: ideological and structural constraints in foreign language education in the US. In T. Huebner, \& K. A. Davis (Eds.), Sociopolitical perspectives in language policy and planning in the USA (pp. 243-66). Amsterdam: John Benjamins.

Paakki, H. (2013). Difficulties in speaking English and perceptions of accents - a comparative study of Finnish and Japanese adult learners of English. University of Eastern Finland: Master's thesis. Retrieved from: https://epublications.uef.fi/pub/urn_nbn_fi_uef20131057/urn_nbn_fi_uef-20131057.pdf

Petersen, S. E., Fox, P., Posner, M., Mintun, M., \& Raichle, M. (1989). Positron Emission Tomographic Studies of the Processing of Single Words. Journal of Cognitive Neuroscience, 1, 153-70.

Pietikäinen, S., \& Kelly-Holmes, H. (2012). The Dangers of Normativity - the Case of Minority Language Media. In J. Blommaert, S. Leppänen, P. Pahta, \& T. Räisänen (Eds.), Dangerous Multilingualism - Northern Perspectives on Order, Purity and Normality (pp. 194-204). Palgrave MacMillan.

Preston, D. (1996). Whaddyaknow?: The modes of folklinguistic awareness. Language awareness, 5, 40-74.

Pujolar, J. (2007). Bilingualism and the nation- state in the post- national era. In M. Heller (Ed.), Bilingualism: a Social Approach (pp. 71-95). Basingstoke: Palgrave Macmillan.

Rydell, M. (2015). Performance and Ideology in Speaking Tests for Adult Migrants. Journal of Sociolinguistics, 19, 535-58.

Schumann, J.H. (1978). The Pidginization Process. Rowley, Massachusetts: Newbury house publishers.

Taavitsainen, I., \& Pahta, P. (2003). English in Finland: Globalisation, Language Awareness and Questions of Identity. English Today, 19, 3-15.

Tatham, M., \& Morton, K. (2006). Speech Production and Perception. New York: Palgrave Macmillan.

Woolard, K. (1998). Introduction: Language ideology as a Field of Inquiry. In B. Schieffelin, K. Woolard, \& P. Kroskrity (Eds.), Language Ideologies: Practice and Theory (pp. 3-51). New York/Oxford: Oxford University Press. 


\section{Appendices}

Appendix 1. Full table of codes.

\begin{tabular}{|c|c|c|c|c|}
\hline & Finland & Japan & Total & Category \\
\hline Accent bias & 93 & 63 & 156 & social \\
\hline Insecurity & 87 & 50 & 137 & affective \\
\hline Comprehension difficulties & 25 & 58 & 83 & cognitive \\
\hline Accuracy bias & 62 & 20 & 82 & instruction \\
\hline Peer pressure & 46 & 33 & 79 & social \\
\hline Lack of use & 32 & 45 & 77 & instruction \\
\hline Grammar-Translation method & 44 & 29 & 73 & instruction \\
\hline Standard model bias & 36 & 33 & 69 & instruction \\
\hline Anxiety & 44 & 24 & 68 & affective \\
\hline Memory retrieval difficulties & 40 & 24 & 64 & cognitive \\
\hline Pronunciation difficulties & 30 & 34 & 64 & cognitive \\
\hline Self-criticism toward own speech & 39 & 22 & 61 & affective \\
\hline Lack of speech practice & 30 & 31 & 61 & instruction \\
\hline Weak ties to TL community & 15 & 35 & 50 & social \\
\hline Level difference & 28 & 10 & 38 & social \\
\hline Linguistic shock & 7 & 30 & 37 & social \\
\hline Lack of exposure & 9 & 26 & 35 & instruction \\
\hline Fear of errors & 27 & 7 & 34 & instruction \\
\hline Limited self-expression & 18 & 12 & 30 & cognitive \\
\hline Can't produce English & 10 & 20 & 30 & cognitive \\
\hline Limited vocabulary & 16 & 11 & 27 & cognitive \\
\hline Non-native speakers easier to talk with & 20 & 6 & 26 & social \\
\hline Passive understanding easier & 14 & 11 & 25 & cognitive \\
\hline Negative experiences & 13 & 12 & 25 & social \\
\hline International communication difficult & 11 & 19 & 30 & social \\
\hline Wish to preserve ethnic identity & 11 & 11 & 22 & social \\
\hline Prestige & 5 & 17 & 22 & social \\
\hline Social awkwardness/introversion & 21 & 16 & 37 & affective \\
\hline Lack of foreign language study & 0 & 18 & 18 & instruction \\
\hline Exclusion from TL community & 8 & 8 & 16 & social \\
\hline Motivational problems & 10 & 2 & 12 & affective \\
\hline Very basic skills & 1 & 11 & 12 & cognitive \\
\hline Difficulty with surprising situations & 9 & 2 & 11 & social/cogn. \\
\hline \multirow[t]{2}{*}{ Culture shock } & 0 & 11 & 11 & affective \\
\hline & 861 & 761 & 1622 & \\
\hline
\end{tabular}


Appendix 2. Code descriptions.

\begin{tabular}{|c|c|}
\hline Code & Description \\
\hline \multicolumn{2}{|l|}{ Affective } \\
\hline Anxiety & $\begin{array}{l}\text { Explicit or indirect reference to the feeling of anxiety or accelerated } \\
\text { heart rate (when speaking/using English). }\end{array}$ \\
\hline Insecurity & $\begin{array}{l}\text { Refers to a lack of self-confidence in TL use. The learner is not } \\
\text { comfortable with using the TL, they feel self-conscious, or there might } \\
\text { be a lack of independence in TL use. }\end{array}$ \\
\hline Culture shock & $\begin{array}{l}\text { A situation in which commonly perceived and understood signs and } \\
\text { symbols of communication do not work in the new culture (e.g. } \\
\text { nonverbal gestures). This might cause loneliness, anger, frustration and } \\
\text { self-questioning of competence (Moyer, 2004; Schumann, 1978). }\end{array}$ \\
\hline Self-criticism & $\begin{array}{l}\text { Self-criticism and/or negative evaluation of one's own spoken English } \\
\text { ("it's stupid/monotonous/stiff/rudimentary/bad English“...). }\end{array}$ \\
\hline Motivational problems & Direct references to problems with motivation. \\
\hline $\begin{array}{l}\text { Social awkwardness/ } \\
\text { introversion }\end{array}$ & $\begin{array}{l}\text { Feeling of social awkwardness or inhibition in social situations } \\
\text { involving_English oral production, or direct references to one being } \\
\text { introverted/shy and thus feeling pressure in these situations. }\end{array}$ \\
\hline \multicolumn{2}{|r|}{ ( } \\
\hline $\begin{array}{l}\text { Exclusion from TL } \\
\text { community }\end{array}$ & $\begin{array}{l}\text { The learner is hesitant to speak because of a feeling of being excluded } \\
\text { from the TL community, e.g. because of a (previous) negative comment } \\
\text { from a community member. }\end{array}$ \\
\hline Level difference & $\begin{array}{l}\text { Preconception of NS (native speaker) superiority. NSs are seen as } \\
\text { owners of the language, judges of grammaticality/correctness, more } \\
\text { difficult to talk to because of their superior language skills, "adults" (as } \\
\text { opposed to learners being "children"), or gatekeepers of the TL } \\
\text { community. }\end{array}$ \\
\hline $\begin{array}{l}\text { Non-native speakers easier } \\
\text { to talk with }\end{array}$ & $\begin{array}{l}\text { Non-native speakers are seen as easier to approach, talk to and/or } \\
\text { understand because of a perceived similarity of proficiency level, } \\
\text { communicative competence, accent or status. }\end{array}$ \\
\hline Negative experiences & Negative social experiences_from speaking English. \\
\hline Accent bias & $\begin{array}{l}\text { Reluctance to speak because of the sting of stigma related to the Finnish } \\
\text { or Japanese accent of English; negative evaluation of one's accent or } \\
\text { another English speaker's non-standard accent, or positive evaluation } \\
\text { of a standard accent as compared to a non-standard one. }\end{array}$ \\
\hline $\begin{array}{l}\text { Difficulty with surprising } \\
\text { situations }\end{array}$ & $\begin{array}{l}\text { TL production becomes difficult in a surprising situation that requires } \\
\text { quick codeswitching from L1 to TL, e.g. giving directions. Often this is } \\
\text { also the most common type of English language interaction the } \\
\text { informants encounter in their daily lives. The context is fixed to L1 use. }\end{array}$ \\
\hline Prestige & $\begin{array}{l}\text { General prestige related to the English language, for example a concept } \\
\text { of internationality, global and successful status. English is seen as the } \\
\text { gate to success, internationality, wealth, and status. }\end{array}$ \\
\hline $\begin{array}{l}\text { International } \\
\text { communication difficult }\end{array}$ & $\begin{array}{l}\text { Difficulty in international communication, easily blamed on low } \\
\text { proficiency, when it really might be due to the situation, variation in } \\
\text { communicative competence or lack of TL communicative strategies. }\end{array}$ \\
\hline Linguistic shock & $\begin{array}{l}\text { Experiencing significant cross-linguistic differences between L1 and TL, } \\
\text { which may be disagreeable to the informant, possibly clouding } \\
\text { perceptions of speakers concerned and causing anxiety, demotivation } \\
\text { and confusion. }\end{array}$ \\
\hline Peer pressure & $\begin{array}{l}\text { The informant is concerned about their peers' evaluations or opinions } \\
\text { regarding his/her English oral production, peers meaning other Finns } \\
\text { or other Japanese people in case of the Japanese data set. }\end{array}$ \\
\hline
\end{tabular}


Weak ties to TL community

Wish to preserve ethnic identity

\section{Instruction and input}

Grammar-Translation methodology

Lack of speech practice Lack of FL study Accuracy bias

Fear of errors

Standard model bias

Lack of exposure

Lack of use Cognitive

Pronunciation difficulties Memory retrieval difficulties

Comprehension problems

Passive understanding easier

Very basic skills

Limited self-expression

Limited vocabulary Can't produce English
The informant has weak or no ties to the TL community, because they use very little or no English in their everyday life, they have no contacts or only distant contacts from the TL community.

Preference of familiar features of one's L1 culture and norms of the L1 ethnic group, and possible avoidance of the features/norms of the TL ethnic group (as in Schumann, 1978). Being proud of one's culture and, for example, showing one's cultural background through accent.

Earlier (or current) education that employed a Grammar-Translation method and/or was accuracy and writing -oriented seems to create a fear of errors and/or a belief that speech should be "perfect", without any mistakes and similar to written TL. Lack of oral exercises, teachercentered model.

A lack of oral exercises in earlier/current English education.

Lack of studying foreign languages in general.

Accuracy-oriented education created a bias of accuracy, i.e., informant believes that accuracy is the most important feature in TL study and production, wanting to speak perfectly or correctly. Hesitation/pressure for performing perfectly. Seeing errors as a serious issue, thinking that there is always a correct model for any TL production.

Essentially related to and coded along with accuracy bias; a separate code for an explicit reference to a fear of errors experienced by the informant.

Idealizing or appreciative references to the Standard model (British English, American English, the "correct" way if it is obviously a reference to the standard codified in educational contexts or text books etc.).

The informant has not been/is not exposed to the TL a lot in their daily life.

Having very little/no opportunities to utilize oral English skills.

Tongue is twisted, cannot pronounce, pronunciation feels difficult etc. Memory related problems in oral production. For example, the learner cannot remember words in an oral production related situation, or experiences slowness in retrieving TL items from memory, which becomes a complicating factor. This linked with age/lack of practice? Trouble understanding the TL input (lexical items, grammar, syntax etc.).

Direct references to passive understanding being easier than active production.

Reference to one's English competence being too basic to speak the language; feeling one cannot form sentences or keep up a conversation.

Having difficulties with speaking, because one experiences limitations in self-expression in the TL. For example, feeling one cannot say exactly what they would like to, but have to settle with a narrow description of their ideas.

Difficulties in oral production because of lacking lexical knowledge. Direct reference to a feeling of not being able to produce any/very little spoken English (despite of theoretical knowledge). 


\section{Appendix 3. Interview questions ${ }^{3}$.}

\section{Background}

1. Age:

2. Gender:

3. Urban/rural background:

4. Mother Tongue:

5. Occupation:

6. Education:

7. Parents' education and occupation:

8. What do you study at the adult education centre (or location of studies)? Why?

9. What languages do you speak?

10. What kind of a speaker are you in your own language? E.g. what have people close to you or your teachers said? Are you a fast or a slow speaker, do you think carefully before speaking, do you talk a lot?

\section{English education}

1. How long have you studied English?

2. How do you feel about studying English?

3. What kind of English teachers or education have you had?

4. Have you rehearsed speaking in English on your English courses? How?

5. Do you think that your English teachers have favoured a particular way of speaking English or a specific accent?

i. Which accent?

ii. Did they have the accent themselves?

6. What kind of an attitude have your teachers had towards the Finnish/Japanese accent of English?

\section{Use of English}

1. Do you use English a lot? How and where? Do you speak it a lot?

2. Do you need English at work? What for?

3. Have you used, or do you use English with your family?

4. Have you ever lived abroad, or do you travel a lot?

5. Do you speak English with pleasure?

6. What kind of experiences do you have on speaking English? Positive/negative?

7. Is English difficult to understand? (Listening, reading)

8. Is speaking English difficult?

i. Why?

ii. Are English words difficult to pronounce, for example? Why (hearing the difference between sounds or producing sounds)?

iii. Is it particularly difficult in some circumstances? Or easier?

9. What do you think you sound like when you speak English?

10. How do you think others see you when you speak English?

i. Are there differences between the attitudes of Finnish/Japanese English speakers and native English speakers?

11. How would you like them to see you?

12. How would you like to speak English?

13. Do you like some English accent more than other accents?

14. Which accent do you like?

15. Which accent do you dislike?

16. How do you feel about the Finnish/Japanese accent of English?

17. Do you know the term "tankeroenglanti" (Finnish interview) / "wasei-eigo" (Japanese interview)? What do you think about it?

18. What could help you in speaking English?

Received April 12, 2019

Revision received April 15, 2020

Accepted June 8, 2020 